\title{
What Drives the Premium for Energy-Efficient Apartments - Green Awareness or Purchasing Power?
}

\section{Carolin Pommeranz ${ }^{1} \cdot$ Bertram I. Steininger $^{2}$ (D)}

Published online: 18 March 2020

(C) The Author(s) 2020

\begin{abstract}
We analyze whether lower rents for energy-inefficient apartments reflect tenants' willingness to pay due to a higher green awareness, purchasing power, or energy consumption costs. Based on a German rental apartment dataset from Q1 2007 to Q1 2019, we use interaction terms for socioeconomic characteristics in a hedonic regression model. We find that rents are lower for apartments with higher energy consumption, even in neighborhoods with lower levels of green awareness. This relationship is stronger in neighborhoods with higher purchasing power, such that communities with low levels of green awareness and high purchasing power show the steepest negative slope for increasing energy consumption $(-8.6 \%$ from the highest to lowest rating). Thus, the rent-decreasing effect of purchasing power is higher than that of green awareness. Splitting the entire period into smaller windows, we find that the interaction effect of green awareness has emerged in the most recent years (2017-2019). This may be driven by changes in regulation, which have made it easier for tenants to assess the energy consumption before they rent, or by a general increase in green awareness over this period.
\end{abstract}

Keywords Energy efficiency · Energy performance certificates · Price differentiation · Consumer behavior

JEL Classification D49 · D82 - Q43 · Q48 · Q51 · R31

Bertram I. Steininger

bertram.steininger@abe.kth.se

1 Munich, Germany

2 Real Estate Economics and Finance, KTH Royal Institute of Technology, Teknikringen 10B, 100 44 Stockholm, Sweden 


\section{Introduction}

The environmental movement has gained influence in the world over the last few decades. Its main goal is protecting the environment and acting against climate change. Carbon dioxide emissions are viewed as an essential cause of environmental pollution and climate change. Some institutions focus on housing - rather than transportation and industry - in order to reduce impact on climate, as housing accounts for $32 \%$ of global final energy consumption, $19 \%$ of energy-related $\mathrm{CO}_{2}$ emissions, and $51 \%$ of global electricity consumption and provides the highest cost-effective savings potential (Lucon et al. 2014).

It would be logical to assume that environmentalists would choose to live in energyefficient housing in order to make their contribution to "saving the planet" or, economically speaking, to gain a higher utility. Such a result would be in line with Kahn's (2007) finding that "greens" in California prefer to commute by public transit, buy hybrid cars, and consume less gasoline. However, Sexton and Sexton (2014) point out that the environmentalists' behavior may be driven by "conspicuous conservation", whereby they seek social status in their (green) community, in addition or rather than by intrinsic motivation. This prosocial behavior is easier to exhibit with a hybrid or electric car parked in front of a garage than with an energy-efficient apartment where the prosocial characteristic is less overt. Thus, our research question concerns whether environmentalists act as they preach, even if their acting is not obviously visible.

The aim of this paper is not to expose hypocritical behavior amongst greens, but rather to identify under which conditions consumers decide to pay less for energy-inefficient apartments, so as to provide policymakers with more insight on how to reach the desired goal of a lower emission. In line with previous research, we also confirm a significant heterogeneity in our results, based on the household behavior and characteristics, which may be addressed in energy efficiency improvement programs. Besides environmental aspects, there might be other influential factors (e.g. heating costs and purchasing power), so we control for these as well. As in other studies, we do not directly observe environmental attitudes and consumption decisions in the same sample, so we have to merge these aspects from different sources. Similar to Kahn (2007), Sexton and Sexton (2014), and Kahn and Kok (2014) using hybrid vehicle or Green Party registrations, we postulate that communities with strong election results for the respective Green Party are a feasible measure for environmentalism (more details in section "The German Rental Market and the Green Party as a Proxy for Environmental Awareness").

In line with previously mentioned literature in the U.S., or Aydin et al. (2018) with a field experiment in the Netherlands, we contribute to the existing literature in explaining why people make different choices (consumer heterogeneity for renting apartments) and why people thereby consume more energy or produce more carbon dioxide emissions, depending on their socioeconomic characteristics (ecological footprint heterogeneity). The key variables for both questions are the consumer's environmental awareness indirectly measured by their election voting, and the purchasing power. In comparison with the previous research, the Green Party in our sample has had a high political influence and has been involved in passing new regulations in recent years. We measure its influence in more detail than previous studies by incorporating the influence of purchasing power as an alternative or amplifying explanatory factor, and time (2007-2019) as environmental awareness has risen. Its influence was further 
strengthened by a new regulation for the housing market effective since May 2014/ 2015 which made it easier for tenants to incorporate the energy consumption of an apartment in their decision-making. Thus, we use the housing market as a laboratory to test whether mandatory disclosure triggers or strengthens a potential rent-decreasing effect of higher energy consumption.

This paper proceeds as follows. In section "Theoretical Background and Hypotheses Development", we provide the theoretical background for our hypotheses. In the next section, we explain our rationale for using a German dataset and Green Party election results as a proxy of environmental awareness. A detailed description of the study area, dataset, and descriptive statistics are given in section "Data". In the next section, we match our empirical model with our theoretical foundation. The results are presented and discussed in section "Results and Discussion". In section "Conclusion", we conclude.

\section{Theoretical Background and Hypotheses Development}

Consumers are generally willing to pay a higher price for higher quality. Landlords anticipate tenants' willingness to pay more (WTP) for higher housing quality, and thus ask for higher rents. Tenants, living in communities which are economically more powerful, are willing to pay more for housing and demand a higher quality of housing. Consistent with this demand, landlords typically offer higher housing quality in such areas. Research shows that environmental awareness, education, and economic wealth are positively correlated. For example, Gamba and Oskamp (2016) find that green consumers have stronger economic power on average based on data from California. Therefore, the green signaling effect for energy-efficient buildings may be an indirect result of the economic power of tenants or an interaction of both - green awareness and economic power - so that we postulate that rents are generally higher in communities that are greener or economically more powerful.

- H1: Monthly rents are higher in greener or economically more powerful communities

In contrast to an apartment's structural attributes (e.g. size), the price range is incrementally higher for 'soft' attributes such as energy efficiency, with intangible or indirect benefits. These aspects are more opaque to consumers and so more variable in value. Higher prices for energy-efficient housing are typically associated with a 'green premium' (e.g. Eichholtz et al. 2010; Kahn and Kok 2014). However, it remains unclear what exactly determines the size of the green premium. Brounen and Kok (2011) show that energy savings due to a better building structure are correlated with higher energy efficiency in the Netherlands but cannot explain the green premium completely; the remainder is driven by non-savings components (Brounen et al. 2013; Fuerst et al. 2016a). Bond and Devine (2016) find a premium for 'green certification' (LEED), in addition to the premium for green living space, and conclude that such certification is an additional information signal in the rental apartment market in the U.S. Fuerst et al. (2016b) identify the 'green signaling effect' as an incentive to invest in energy-efficient housing for 'green' consumers in Helsinki. They emphasize that this premium, which implies benefits that go beyond energy savings, only applies to top-tier 
energy ratings and is a proxy for the WTP of green consumers. Mandell and Wilhelmsson (2011) confirm a generally higher WTP for environmental attributes in Swedish households that perceive themselves as environmentally aware. Aydin et al. (2017) analyze the rebound effect (reduction of the initial efficiency gains) in the residential sector and find a rebound effect of around $41 \%$ among tenants. The results vary with household wealth and income. Owners and tenants may also face nonmonetary costs of energy efficiency which reduce their willingness to invest or live in such buildings even if public money is available to subsidize such investments (see, for example, Fowlie et al. 2015).

We add to this research by disentangling people's motivation to pay a higher price for energy-efficient buildings and focusing on the socioeconomic characteristics of the apartment neighborhood. Residents of energy-efficient buildings may have different reasons why they are mostly willing to pay a premium in order to live in such buildings. On the one hand, energy efficiency reduces the cost of heating and cooling, so they may be purely economically driven. However, Brounen et al. (2013) and Fuerst et al. (2016a) show that even after taking the energy cost into account, energy-efficient buildings are still bought/ rented with a premium. They conclude that this may be driven by non-energyrelated effects linked with certain specifications of the dwellings or by unobserved quality differences unrelated to energy performance (e.g. quality fittings and materials). On the other hand, residential and commercial housing is one of the main contributors to world-wide energy consumption with its lighting, heating, cooling, and using appliances. Thus, environmentalists can reduce their personal ecological footprint more easily through housing than through their consumption of other goods and should consequently be looking for energyefficient housing if they want to act sustainably.

However, their prosocial lifestyle is not as visible with an energy-efficient apartment as with a hybrid or electric car parked in front of their garage. Therefore, the argument of "conspicuous conservation" (see Sexton and Sexton 2014) may be weaker for housing. Sexton and Sexton (2014) theoretically elaborate and empirically prove that people act in order to express prosocial behavior (e.g. environmental protection): in other words, "they act as they preach" to attain a higher environmental status and name this "conspicuous conservation". This is in line with the traditional "conspicuous consumption" theory, where people buy luxury products in order to express their wealth and seek status in their community.

Furthermore, the positive effect of energy-efficient housing is not as questionable as for hybrid or electric cars. Even if there are concerns about the total life cycle energy consumption of energy-efficient dwellings (taking into account the "grey" energy required for producing, transporting, and recycling energy-saving materials), this is less critically discussed than, for example, the implications of e-cars with their lithiumion batteries. Some researchers conclude that the life cycle consumption of energy is even higher for e-cars than for traditional cars. Moreover, the social consequences of mining the necessary raw materials in developing countries may counteract the original good intentions behind e-cars. Thus, we assume that the willingness to pay for energyefficient housing is more pronounced for environmentalists, as their positive effects on the environment are more obvious. Against the background of our theoretical overview, we formulate the following major hypotheses: 
- H2a: Monthly rents are decreasing for higher energy consuming apartments in greener communities.

As this may be also driven by the economic wealth of a community (see discussion for H1 or, for example Aydin et al. 2017), we extend this hypothesis to this aspect as well.

- H2b: Monthly rents are decreasing for higher energy consuming apartments in more economically powerful communities.

We abstain from postulating hypotheses for rents in communities that are both greener and economically more powerful at the same time and how these factors influence the rent if the energy consumption of an apartment increases. We leave this to our empirical analysis in section "Results and Discussion".

In recent years, the environmental movement has gained momentum. Environmental protection is both prominently highlighted by figureheads such as Al Gore in the U.S. or Greta Thunberg in Europe accompanied with high media coverage, and is continuously pursued by Green parties, which are more powerful in Europe than in other parts of the world. Their popularity is even stronger in our data sample in Germany, where the Green Party (Bündnis 90/Die Grünen) reached 20.5\% of the vote in the last country-wide 2019 election for the European Parliament, with a relative majority in the largest cities. Therefore, we assume that the decreasing effects of $\mathrm{H} 2 \mathrm{a} / \mathrm{b}$ have become more pronounced over time and may even have been insignificant a decade ago.

- H3: The fall in rents for apartments with higher energy consumption (H2a/b) has intensified over the years.

This effect may have been strengthened by a regulation change effective since May 2014, whereby EPC labels are required to show a rating in letters $\left(\mathrm{A}^{+}\right.$to $\left.\mathrm{H}\right)$ in addition to the energy value in $\mathrm{kWh} / \mathrm{m}^{2} \mathrm{a}$. Furthermore, landlords must give this information in our used data sample or confirm that they will show the EPC document (figure in $\mathrm{kWh} / \mathrm{m}^{2} \mathrm{a}$ and rating by letter) to potential tenants during the apartment viewing, before they decide to rent. Such information is also often available on the notice board of the entrance hall. This mandatory and clear comparison tool makes it easier for potential tenants to assess the energy efficiency of an apartment before they make their renting choice. The regulators gave landlords a phase-in period of one year, so we assume that the market was more transparent after May 2015 and the probability of observing our hypothesis $\mathrm{H} 2 \mathrm{a}$ (not $\mathrm{H} 2 \mathrm{~b}$ ) is more likely since then. Therefore, our sample gives us the opportunity to test the effect of energy efficiency in the contexts of both voluntary and mandatory disclosure - thus contributing to the literature.

Besides the influence of green and economic power, rents may be influenced, directly or indirectly, by other sociodemographic factors; these unobserved variables may correlate with energy efficiency, energy consumption, or rent. For example, communities with a higher unemployment rate may have lower prices or different energy consumption (for more information about energy consumption see, for example, Aydin et al. 2017). Thus, we control for other sociodemographic factors (household 
size, number of households, immigration rate, and unemployment) in our empirical analysis. Energy performance correlates with other housing attributes such as age: typically, newer buildings have lower energy consumption. In order to exclude the effect of such housing attributes, we incorporate apartment size, number of rooms, age, and quality, too. However, a limitation to our research is that there may be more relevant housing attributes linked with energy efficiency such as newer construction material or the direction of the apartment/balcony in relation to the sun. Such priceincreasing attributes are not separated from the energy performance value in our empirical analysis and may influence our results.

\section{The German Rental Market and the Green Party as a Proxy for Environmental Awareness}

\section{Rental Housing Market}

We analyze the consumer and price differentiation in North Rhine-Westphalia (NRW), the most densely populated federal state in Germany with about 18 million citizens. NRW includes two of the seven largest German cities ${ }^{1}$ and, with 5.1 million people, the largest metropolitan area in Germany. The housing market in NRW can be seen as very similar to the general market in Germany. Houses are mostly privately owned (Germany $84 \%$, NRW 83\%), whereas apartments are mostly rented (Germany 78\%, NRW $79 \%$ ) - the home-ownership ratio is low in comparison to the European average of $70.1 \%$ (Germany $46.5 \%$, NRW 43.7\%). Due to lower affordability, this ratio is lower in larger cities, e.g. Berlin 17.2\%, Düsseldorf $19.3 \%$, and Cologne $24 \%{ }^{2}$ In comparison to other countries, Germany has a large and well-functioning rental housing market. Rental regulation favors the tenants and the quality of housing is high (see for example, Eurostat 2018). In addition to quality, a strong supply of apartments in towns/cities together with high transaction costs for buying a property (round-trip costs are around $12.7 \%)^{3}$ make it attractive for all income groups to rent. Therefore, renting - even if negatively correlated with income - is not a clear indicator of a person's wealth, unlike in other countries (e.g. the Netherlands or the U.K.) where rented dwellings are often state-owned or part of social housing projects. Based on the micro census of the public NRW.Bank (2018), the majority of single-households are renters, whereas around half of households with or without children own a dwelling. Of these owners, $19 \%$ live in two-family houses, $58 \%$ in single-family houses, and $23 \%$ in apartment buildings. The dwellings are not held by a limited number of rental companies which own whole apartment blocks, but rather by a mixture of large profit-oriented companies, SMEs, non-profit building societies, and (semi-) private landlords who own one or a few apartments as an investment opportunity. These private landlords and SMEs make up the majority, owning around two thirds of rental properties.

Renting a home is the most common living arrangement in Germany, and therefore we use only rental apartments in our empirical analysis. Furthermore, these are more

\footnotetext{
${ }^{1}$ Cologne and Düsseldorf; the other largest cities are Berlin, Frankfurt, Hamburg, Munich, and Stuttgart.

${ }^{2}$ Based on data of Destatis (Federal Statistical Office of Germany) and municipally statistical offices for 2018.

${ }^{3}$ Based on Global Property Guide Research.
} 
homogeneous in their property attributes compared to other housing types, which streamlines the identification of relevant hedonic characteristics. Rental periods are typically shorter (around 8 years) than an average homeownership duration (around 20 years), so tenant turnover is more frequent and energy-efficient rental apartments are more easily accessible to green-sensitive people (Bond and Devine 2016). Summing up, the rental data on apartments may provide a better indicator of individual energy efficiency valuation than other housing data and may influence our results, too.

\section{Green as a Proxy for Environmental Awareness}

The environmental movement has gained momentum in Europe. The political group of the "Greens/European Free Alliance" won around 10\% of all seats in the last election to the European Parliament in May 2019. Across different political groups, environmental topics have great importance at the European level. The Directives 2010/31/EU and 2012/27/EU of the European Parliament and Council set new definitions and rules to improve the energy performance of buildings and energy efficiency in general in all member states. These legal initiatives prompted financial subsidy and funding programs to reduce primary energy consumption by buildings in Europe, supported by national and state-wide organized energy efficiency programs.

In Germany, the "green" political pressure group started with various grassroots movements against nuclear energy and for peace, and environmental protection, together with new social movements in the 1970s and 1980s. The Green Party (Bündnis 90/Die Grünen) has achieved a higher level of influence in Germany, both on the state and federal level, than in other European countries. On the federal level, it was founded as a Party in 1980, won its first seats in the Parliament in 1983, and acted as a junior partner in the governing coalition between 1998 and 2005. In the last country-wide election for the European Parliament in May 2019, it secured 20.5\% of the vote and even gained relative majorities in the seven largest cities. ${ }^{4}$ At the moment, it is governing in 9 of the 16 German states, and in one even as the larger coalition partner.

In the state of NRW analyzed here, the Green Party has had members in the Parliament since 1990 and was in the state government as a minor coalition partner between 1995 and 2005 and 2010-2017 with state-wide voting results between 5\% and $12 \%$. The party refuses to follow a specific political ideology but declares that it follows specific fundamental values. Its original 1980s political program incorporates social justice, ecological wisdom, grassroots democracy, and non-violence; in 2002 it was updated to include ecology, self-determination, justice, and democracy under the umbrella term "the future is green". In the election program of 2012, a specific aim of the "green new deal for NRW", was the reduction of emissions in the housing sector by increasing the stock of energy-efficient buildings. ${ }^{5}$ The relative importance of environmental issues in the society and the influence of the green political groups led to early

\footnotetext{
${ }^{4}$ In the real estate sector in Germany, the Big-7 is a collective term for the 7 largest and most important cities of which 2 are in the sample state of North Rhine-Westphalia. The cities have a high influence on the surrounding region and are (descending order): Berlin, Hamburg, Munich, Cologne, Frankfurt, Stuttgart, and Düsseldorf.

${ }^{5}$ The full political program is available at https://gruene-nrw.de/dateien/gruenes-wahlprogramm-nrw-2012 gruener-zukunftsplan-update.pdf.
} 
energy-efficient regulations and even extreme concepts of ultra-low energy buildings (passive houses). Federal and state governments attach great importance to energysaving regulation as a key instrument of energy and climate protection for the next decades, with the aim to have a nearly climate-neutral building stock by the year 2050 .

\section{Data}

\section{Pricing Data and Structural Attributes}

The property dataset is provided by ImmobilienScout24, which is one of the leading online platforms for property offerings in Germany. It includes all rental apartment offerings made by using this service during the Q1 2007-Q1 2019 sample period. However, the observation number is rather low in the first years (2007-2010) so that we later control for that by splitting our sample into smaller time windows. A general overview of this dataset, which is available for academic research, is given by Boelmann and Schaffner (2018). We use all observations which have valid values for our used variables. ${ }^{6}$

In Germany, only the rents asked are available for hedonic models, since the actual rent prices are not systematically collected with the most important structural attributes (e.g. number of rooms or age). The interpretation of rents asked may be biased, as landlords intentionally over- or underestimate achievable rents. Since landlords usually attempt to achieve a high rent in a short offering time and inflated rents may lead to a significant increase in the offering time (Yavas and Yang 1995), we include the offering time in our models to control for possible distortion of rents asked. However, the average rent asked per square meter in our dataset amounts to $€ 7.38$ compared to an average actual rent of $€ 6.86$ for existing buildings and $€ 8.70$ for new buildings with a simple average for both groups of $€ 7.78 .^{7}$ Our sample intentionally consists only of new potential rental contracts resulting in a higher average of the rental price. However, there is no indication that the price and the exploratory variables are systematically biased between the rental offers on the platform used and prices on the entire market. Overall, we use 377,426 valid observations in our analysis.

Furthermore, the dataset contains information on structural attributes such as apartment size, number of rooms, age, and quality. We include the living area in square meters (sqm) and age as continuous variables. While the number of rooms is discrete, the variable for quality is categorical, with the following classification: luxury, good, normal, and simple. Table 1 provides the descriptive statistics. The average monthly

\footnotetext{
${ }^{6}$ We exclude an observation if the data provider flags the observation as "missing", "not specified", or "implausible value". Furthermore, we exclude observations identified as duplicates by the provider. For that, we use two provided identifiers "probably the same offer" and "offer close in time ( $\leq 6$ months) with the same attributes". We assume that these offers are teaser announcements which are "refreshed" in order to appear again in the newest offer list with enhanced appeal. We include them only for their first occurrence and if the time span is longer than 6 months.

${ }^{7}$ Actual rental prices are obtained from bulwiengesa AG, a company specialized in data services, analysis, appraisal, and consulting of real estate in Germany. It has collected data since 1986 and is the major source for quantitative analysis (e.g. forecasts and index calculation) in the residential and commercial market. It cooperates with the German Bundesbank in compiling the official real estate index for Germany and the major cities.
} 
rent is $€ 7.38$ per sqm. The average time on the market is 1 month. Apartments are on average 48 years old and have a living area of $72 \mathrm{sqm}$. About $3 \%$ of the properties are classified as luxury, $39 \%$ as good, $57 \%$ as normal, and $2 \%$ as simple.

\section{Energy Characteristics}

The apartment's energy consumption ( $E P C$, energy performance certificate) is the key variable for our analysis. Thus, we focus on an apartment's EPC value (e.g. $130 \mathrm{kWh} /$ $\mathrm{m}^{2} \mathrm{a}$ ) corresponding to an EPC rating of D that was introduced in May 2014/2015 as an additional information tool to motivate individuals to incorporate energy efficiency in their decision making. Although providing information in the EPC is generally mandatory for advertisements, there are permissible exemptions. However, those observations with missing EPCs cannot be included in our analysis. As we assume a decreasing impact of energy consumption, we use the natural logarithm of the energy efficiency value $(\log (E P C))$.

Regarding regulation, two different types can be used to determine the EPC value: the consumption-based ( $72 \%$ of our sample) and the requirement-based (28\%) type. To account for a potentially different impact of these two types, we include a dummy variable for the EPC type (EPC Requirement) assuming a positive effect for the requirement-based type since it is more detailed but also more expensive in the issuance for the landlords and therefore less frequent.

Furthermore, EPC labels obtained after May 1, 2014 must provide the energy efficiency value in letters ranging from $\mathrm{A}^{+}$for the highest to $\mathrm{H}$ for the lowest efficiency level, according to the German classification system. This rating should help individuals to compare energy efficiency across properties and may result in a preference for apartments providing this information. Thus, we also include a dummy variable (EPC with Rating) for whether the energy value is additionally stated as a letter, as is the case for $12 \%$ of our sample. To make the entire data sample processible for our descriptive statistics, we additionally state the letter for observations with missing ratings according to the classification system: EPC $\mathrm{A}^{+}\left(<30 \mathrm{kWh} / \mathrm{m}^{2} \mathrm{a}\right), \mathrm{EPC}$ A $\left(30-50 \mathrm{kWh} / \mathrm{m}^{2} \mathrm{a}\right)$, EPC B $\left(50-75 \mathrm{kWh} / \mathrm{m}^{2} \mathrm{a}\right)$, EPC C $\left(75-100 \mathrm{kWh} / \mathrm{m}^{2} \mathrm{a}\right)$, EPC D (100-130 kWh/m²a), EPC E (130-160 kWh/m²a), EPC F (160-200 kWh/m²a), EPC G $\left(200-250 \mathrm{kWh} / \mathrm{m}^{2} \mathrm{a}\right)$, and $\mathrm{EPC} \mathrm{H}\left(>250 \mathrm{kWh} / \mathrm{m}^{2} \mathrm{a}\right)$. If observations with missing ratings have a systematic lower price, we indicate this with the dummy variable $E P C$ with Rating. The average energy value is $129.6 \mathrm{kWh} / \mathrm{m}^{2} \mathrm{a}$, which equals EPC D. Most apartments have the rating D (24\%), followed by E (21\%) and C (15\%). Descriptive statistics for energy ratings are presented in Table 1.

\section{Socioeconomic Characteristics and Distances}

In order to verify our hypotheses (see section "Theoretical Background and Hypotheses Development"), we refer to environmental awareness and economic power. As a proxy for environmental awareness, we use data about the Green Party's election results during the federal state election in $2012 .{ }^{8}$ The results are available at the electoral district level and vary from $4.7 \%$ to $19.6 \%$ of the vote with a mean of $12.5 \%$. For a robustness test, we use the

\footnotetext{
${ }^{8}$ We prefer to use a state election instead of federal or European elections since we assume that environmental and housing aspects are more the focus of state elections.
} 
Table 1 Descriptive Statistics

\begin{tabular}{|c|c|c|c|c|}
\hline & Mean & Std. Dev. & Min. & Max. \\
\hline Monthly Base Rent per sqm $(€)$ & 7.38 & 2.43 & 1.00 & 48.51 \\
\hline Annual Costs for Utilities per sqm $(€)$ & 2.04 & 0.78 & 0.00 & 25.00 \\
\hline Annual Heating Costs per sqm $(€)$ & 0.90 & 0.42 & 0.01 & 8.83 \\
\hline Time on Market (months) & 1.04 & 1.49 & 0.03 & 58.60 \\
\hline \multicolumn{5}{|l|}{ Structural Attributes } \\
\hline Living Area (sqm) & 71.67 & 26.80 & 9 & 480 \\
\hline Number of Rooms & 2.61 & 0.91 & 1 & 10 \\
\hline Floor & 2.83 & 1.48 & 0 & 46 \\
\hline Age (years) & 48.19 & 28.08 & 0 & 169 \\
\hline \multicolumn{5}{|l|}{ Structural Quality (\%) } \\
\hline Luxury & 2.72 & 16.28 & 0 & 100 \\
\hline Good & 38.75 & 48.72 & 0 & 100 \\
\hline Normal & 56.84 & 49.53 & 0 & 100 \\
\hline Simple & 1.69 & 12.87 & 0 & 100 \\
\hline \multicolumn{5}{|l|}{ Sociodemographic and Economic Characteristics } \\
\hline Green Party $(\%)$ for State Election in 2012a & 12.54 & 3.56 & 4.71 & 19.56 \\
\hline Green Party (\%) for Federal Election in $2013^{a}$ & 8.79 & 2.74 & 3.00 & 15.17 \\
\hline Annual Household Purchasing Power $(€)$ & $42,397.69$ & 6855.42 & $26,429.98$ & $72,768.23$ \\
\hline Household Size & 2.00 & 0.17 & 1.59 & 2.73 \\
\hline Number of Households & $11,798.88$ & 4508.54 & 996 & 29,586 \\
\hline Immigration Rate (\%) & 11.58 & 6.20 & 1.10 & 43.23 \\
\hline Unemployment Rate $(\%)$ & 4.94 & 1.46 & 0.89 & 13.36 \\
\hline \multicolumn{5}{|l|}{ Distances (meter) to Nearest } \\
\hline Park & 564.65 & 576.73 & 4.20 & $12,139.74$ \\
\hline Motorway & 2699.90 & 2848.89 & 3.69 & $47,311.77$ \\
\hline Education or Health Facility & 852.86 & 875.89 & 9.04 & $10,536.60$ \\
\hline \multicolumn{5}{|l|}{ EPC - Energy Label Type (\%) } \\
\hline Consumption Label & 71.71 & 45.04 & 0 & 100 \\
\hline Requirement Label & 28.29 & 45.04 & 0 & 100 \\
\hline \multicolumn{5}{|l|}{$\mathrm{EPC}-$ Rating $(\%)^{\mathrm{b}}$} \\
\hline Labels with Rating & 12.04 & 32.55 & 0 & 100 \\
\hline Labels without Rating & 87.96 & 32.55 & 0 & 100 \\
\hline EPC - Energy Value $\left(\mathrm{kWh} / \mathrm{m}^{2} \mathrm{a}\right)$ & 129.62 & 54.16 & 0.01 & 592 \\
\hline \multicolumn{5}{|l|}{ EPC - Energy Label ${ }^{\mathrm{b}}(\%)$} \\
\hline $\mathrm{A}^{+}$ & 1.97 & 13.90 & 0 & 100 \\
\hline A & 2.88 & 16.72 & 0 & 100 \\
\hline B & 9.54 & 29.38 & 0 & 100 \\
\hline $\mathrm{C}$ & 15.03 & 35.74 & 0 & 100 \\
\hline $\mathrm{D}$ & 24.14 & 42.79 & 0 & 100 \\
\hline E & 20.98 & 40.72 & 0 & 100 \\
\hline
\end{tabular}


Table 1 (continued)

\begin{tabular}{lllll}
\hline & Mean & Std. Dev. & Min. & Max. \\
\hline F & 16.31 & 36.95 & 0 & 100 \\
G & 6.58 & 24.79 & 0 & 100 \\
H & 2.57 & 15.81 & 0 & 100 \\
\hline
\end{tabular}

The table provides the descriptive statistics for 377,426 observations. Std. Dev. stands for standard deviation, Min. is the minimum, and Max. the maximum of each variable. a The mean value of the Green Party's election result is higher in our sample compared to the official figures due to more observations in environmentally aware neighborhoods - official figures are $11.3 \%$ (2012) and $8.0 \%$ (2013). b Only EPC labels issued after May 2014 are required to display the energy value in letters from $\mathrm{A}^{+}$to $\mathrm{H}$. For comparability, energy classes for the data sample are calculated from the EPC value in $\mathrm{kWh} / \mathrm{m}^{2}$ a using following scheme: EPC A ${ }^{+}\left(\leq 30 \mathrm{kWh} / \mathrm{m}^{2} \mathrm{a}\right), \operatorname{EPC~A~}\left(30-50 \mathrm{kWh} / \mathrm{m}^{2} \mathrm{a}\right), \operatorname{EPC~B}\left(50-75 \mathrm{kWh} / \mathrm{m}^{2} \mathrm{a}\right), \operatorname{EPC~C}$ $\left(75-100 \mathrm{kWh} / \mathrm{m}^{2} \mathrm{a}\right)$, EPC D $\left(100-130 \mathrm{kWh} / \mathrm{m}^{2} \mathrm{a}\right)$, EPC E $\left(130-160 \mathrm{kWh} / \mathrm{m}^{2} \mathrm{a}\right)$, EPC F $\left(160-200 \mathrm{kWh} / \mathrm{m}^{2} \mathrm{a}\right)$, EPC G $\left(200-250 \mathrm{kWh} / \mathrm{m}^{2} \mathrm{a}\right)$, and EPC H $\left(\geq 250 \mathrm{kWh} / \mathrm{m}^{2} \mathrm{a}\right)$

results of the federal election in 2013 in our empirical analysis as well; the voting results for this election range from $3.0 \%$ to $15.2 \%$ with a mean of $8.8 \%$. The annual household purchasing power serves as our proxy for economic power and may be an alternative or amplifying factor besides the influence of the environmental awareness. The data are obtained from GfK GeoMarketing on the postal code level. The purchasing power varies from $€ 26,430$ to $€ 72,768$ with a mean of $€ 42,398$.

There is an improvement in the degree of fit when detailed neighborhood characteristics are employed in a hedonic analysis, since they control for unobserved variables (e.g. Hilber 2005), so we incorporate these control factors as well. The sociodemographic characteristics include the number of households, household size, and migration at the postal code level. This information is obtained from GfK GeoMarketing. The unemployment rate at the municipality or LAU level (Local Administrative Units; previously NUTS 4 and NUTS 5) is obtained from the Federal Employment Agency (Bundesagentur für Arbeit).

Since the proximity of amenities can directly and indirectly affect an apartment's valuation, we also calculate the geodesic distance from the apartment location to the nearest park, the nearest highway, and the nearest education or health facility in three different variables. The apartment location is available to us within the European INSPIRE 1-skm grid system, so we calculate the natural logarithm of the linear distance from the middle point of the raster cell to the next amenities. For more details regarding descriptive statistics, see Table 1.

\section{Model}

\section{Baseline Analysis}

With our empirical approach, we examine the price differentiation of energy efficiency using hedonic regression models and divide our research design into two different steps. In the first step, we neglect the potential impact of environmental behavior or 
economic power and regress the monthly base rent on different explaining factors by using a hedonic regression model based on the following equations:

$$
\log \left(R_{i t}\right)=\alpha+\beta_{1} \log \left(E P C_{i}\right)+\delta X_{\mathrm{i}}+\mu Q_{t}+\eta S_{i}+\varepsilon_{i t}
$$

The dependent variable is the natural logarithm of monthly base rent per sqm $\left(\log \left(R_{i t}\right)\right)$ for apartment $i$ at time $t$. The key explanatory variables are the natural logarithm of the energy efficiency value $(\log (E P C))$ and the energy-related variables of matrix $X_{i}$ including the EPC type (EPC Requirement), EPC value is additionally stated with a rating (EPC with Rating), annual costs for utilities per sqm (log (Utilities' Cost)), and annual heating costs per sqm (log (Heating Cost)). This matrix also includes market and structural attributes (Time on Market, Living Area, Number of Rooms (base and squared form), Floor, Age (base and squared form), structural quality (Luxury, Good, Normal, Simple), sociodemographic characteristics (Household Size, Number of Households, Immigration Rate, Unemployment Rate), and distances to nearest amenities (Park, Motorway, Education, Health Facility) in the natural logarithm. $Q_{t}$ are quarterly time-fixed effects, $S_{i}$ are spatial-fixed effects at different levels, and $\varepsilon_{i t}$ is an independent and identically distributed random error term. We control for unobserved heteroscedasticity (time and spatial). Summing up, we determine price effects for the EPC value without taking the heterogeneous tenants' characteristics regarding environmental behavior or economic power into account. This procedure is in line with other research (e.g. Fuerst et al. 2015) so that we can compare our baseline analysis with their and our later results.

\section{Impact of Green and Purchasing Power}

In the next step, we test our hypotheses (H1, H2a/b, and H3) and expand our Eq. (1) with data about the Green Party's election results (Green, in \%) and the annual household purchasing power $(P P$, in $€ 10,000)$ at the apartment's postal code area to test how environmental behavior and economic power influence the apartment's rent. We are interested not only in the socioeconomic variables' base effect but also in whether they amplify the potential negative effect of the EPC value on the rental price (see the following equation):

$$
\begin{gathered}
\log \left(R_{i t}\right)=\alpha+\beta_{1} \log \left(E P C_{i}\right)+\beta_{2} \text { Green }_{i}+\beta_{3} P P_{i} \\
\ldots+\gamma_{1} \ln \left(E P C_{i}\right) \times \text { Green }_{i}+\gamma_{2} \ln \left(E P C_{i}\right) \times P P_{i}+\gamma_{3} \text { Green }_{i} \times P_{i}+\gamma_{4} \ln \left(E P C_{i}\right) \times \text { Green }_{i} \times P_{i} P_{i} \\
\ldots+\delta X_{i}+\mu Q_{t}+\eta S_{i}+\varepsilon_{i t} .
\end{gathered}
$$

In our analysis, we are mostly interested in the base effect of the two socioeconomic variables $($ Green and $P P)$ and the first two interaction terms $((\log (E P C)$ x Green $)$ and $(\log (E P C) \times P P))$. We assume that the base effects $\left(\beta_{2}, \beta_{3}\right)$ increase the rental prices, while the interactions $\left(\gamma_{1}, \gamma_{2}\right)$ have a negative impact.

\section{Results and Discussion}

We divide our empirical analysis into three different steps. First, we determine the general impact of the EPC value on rental prices to verify previous research. 
Second, we test whether the socioeconomic characteristics (environmental awareness and economic power) amplify these effects. Third, we check whether the interactions of socioeconomic characteristics and EPC have increased over our observation period; in particular, after the mandatory disclosure of the EPC value and rating in May 2014/2015.

\section{General Impact of EPC Value}

In Table 2, we present the results for the general impact of EPC and other energy-related key variables in different model specifications in order to check whether our results are robust. Model 1, excluding the Distance and Sociodemographic variables, shows that a $1 \%$ increase in the EPC value decreases the rental price by around $2 \%$. This is in line with previous research for the office or residential market in the U.S. and Europe using EPC value or ratings (e.g., Eichholtz et al. 2010; Kok and Jennen 2012; Fuerst et al. 2015). Both the requirement-based EPC type as well as an EPC additionally stating the

Table 2 Baseline Analysis

\begin{tabular}{|c|c|c|c|c|c|c|c|}
\hline & Model 1 & Model 2 & Model 3 & Model 4 & Model 5 & Model 6 & Model 7 \\
\hline $\log (E P C)$ & $\begin{array}{l}-0.020 * * * \\
(0.002)\end{array}$ & $\begin{array}{l}-0.017^{* * *} \\
(0.002)\end{array}$ & $\begin{array}{l}-0.017^{* * *} \\
(0.002)\end{array}$ & $\begin{array}{l}-0.026^{* * *} \\
(0.001)\end{array}$ & $\begin{array}{l}-0.017^{* *} \\
(0.003)\end{array}$ & $\begin{array}{l}-0.012 * * * \\
(0.002)\end{array}$ & $\begin{array}{l}-0.017 * * \\
(0.003)\end{array}$ \\
\hline EPC Requirement & $\begin{array}{l}0.030 * * * \\
(0.001)\end{array}$ & $\begin{array}{l}0.030^{* * * *} \\
(0.001)\end{array}$ & $\begin{array}{l}0.029^{* * *} \\
(0.001)\end{array}$ & & $\begin{array}{l}0.029 * * * \\
(0.003)\end{array}$ & $\begin{array}{l}0.032 * * * \\
(0.001)\end{array}$ & $\begin{array}{l}0.029 * * * \\
(0.003)\end{array}$ \\
\hline EPC with Rating & $\begin{array}{l}0.014 * * * \\
(0.002)\end{array}$ & $\begin{array}{l}0.014 * * * \\
(0.002)\end{array}$ & $\begin{array}{l}0.014 * * * \\
(0.001)\end{array}$ & & $\begin{array}{l}0.014 * * * \\
(0.003)\end{array}$ & $\begin{array}{l}0.007 * * * \\
(0.002)\end{array}$ & $\begin{array}{l}0.014 * * * \\
(0.003)\end{array}$ \\
\hline $\log \left(\right.$ Utilities' Cost $\left.^{\prime}\right)$ & $\begin{array}{l}0.027 * * * \\
(0.002)\end{array}$ & $\begin{array}{l}0.027 * * * \\
(0.002)\end{array}$ & $\begin{array}{l}0.023 * * * \\
(0.002)\end{array}$ & $\begin{array}{l}0.023 * * * \\
(0.002)\end{array}$ & $\begin{array}{l}0.023 * * * \\
(0.003)\end{array}$ & $\begin{array}{l}0.027 * * * \\
(0.002)\end{array}$ & $\begin{array}{l}0.023 * * * \\
(0.003)\end{array}$ \\
\hline $\log$ (Heating Cost) & $\begin{array}{l}-0.005^{* *} \\
(0.002)\end{array}$ & $\begin{array}{l}-0.006^{* * *} \\
(0.002)\end{array}$ & $\begin{array}{l}-0.009 * * * \\
(0.002)\end{array}$ & & $\begin{array}{l}-0.009 \\
(0.008)\end{array}$ & $\begin{array}{l}-0.017 * * * \\
(0.002)\end{array}$ & $\begin{array}{l}-0.009 \\
(0.008)\end{array}$ \\
\hline Structural & Yes & Yes & Yes & Yes & Yes & Yes & Yes \\
\hline Distance & No & Yes & Yes & Yes & Yes & Yes & Yes \\
\hline Sociodemographic & No & No & Yes & Yes & Yes & Yes & Yes \\
\hline Time FE & Yes & Yes & Yes & Yes & Yes & Yes & Yes \\
\hline Spatial FE & Political & Political & Political & Political & Political & Labor & Political \\
\hline SE cluster & Time & Time & Time & Time & Spatial & Time & Time/Spatial \\
\hline$N$ & 377,426 & 377,426 & 377,426 & 378,453 & 377,426 & 377,426 & 377,426 \\
\hline Adj. $\mathrm{R}^{2}$ & 0.678 & 0.682 & 0.708 & 0.706 & 0.708 & 0.660 & 0.708 \\
\hline
\end{tabular}

Resulting from the hedonic models stated in Eqs. (1), this table presents coefficients for the natural logarithm of the energy efficiency value $(\log (E P C))$, dummies whether the EPC type is requirement-based $(E P C$ Requirement) and EPC rating is available in letters (EPC with Rating), and the natural logarithms of the annual utilities cost without heating per square meter (log (Utilities' Cost)) and heating costs per square meter (log (Heating Cost)). Additional explanatory variables are structural attributes (Structure), distance to amenities (Distance), sociodemographic characteristics of the postal code (Sociodemographic), and quarterly time-fixed effects (Time FE) as well as political or labor market clustered spatial-fixed effects (Spatial FE). Dependent variable is the natural logarithm of the monthly base rent per square meter (€/p.m./sqm). Standard errors (SE) are clustered by time or spatial dummies and presented in parentheses. $* p<0.1, * * p<0.05, * * * p<0.01$ 
letter $\left(\mathrm{A}^{+}-\mathrm{H}\right)$ have a positive effect, $(0.03)$ and $(0.014)$, respectively. Tenants seem to regard this information as an added value, as the requirement-based EPC is more detailed and a rating is easier to assess than a value in $\mathrm{kWh} / \mathrm{m}^{2} \mathrm{a}$. A $1 \%$ increase in the costs for utilities (water, waste collection, etc.) has a positive effect $(2.7 \%)$, while the effect of heating costs is negative $(-0.5 \%)$. Thus, the rent is not only decreased by the direct costs of energy inefficiency (log (Heating Cost)) but also by the EPC value $(\log (E P C))$. As for all models, we include all structural variables and quarterly time-fixed effects. In order to incorporate unobserved regional similarities which may drive the rent, energy efficiency or energy consumption, we include spatial-fixed effects based on a political district level (NUTS 3). The standard errors are clustered by quarterly dummies. All parameters are statistically significant at least at a level of 5\% and Model 1 is able to explain around $68 \%$ of the variation.

The key parameters are similar for the other model specifications. In Model 2, we include distances to the nearest amenities (park, motorway, education, health facility) to control for a positive effect from better infrastructure; in Model 3, we add sociodemographic variables (household size, number of households, immigration rate, unemployment rate) to control for the influence of different sociodemographic factors on rent or energy consumption; in Model 4, we exclude the direct cost variables (utilities and heating) to verify that the key parameters are still significant; in Model 5, we cluster the standard errors not by quarterly dummies but by spatial dummies; in Model 6, we exchange the spatial-fixed effect with labor market organized regions (see Kosfeld and Werner 2012, for more details); and in Model 7, we double cluster the standard errors by quarterly and spatial dummies. The direct cost of energy inefficiency $(\log ($ Heating Cost) $)$ is not significant if we control for spatial-fixed effects so that this factor is regionally dependent. As the coefficients and significance levels are very similar among the different model specifications, we proceed with the specification with the highest adjusted $R^{2}$ and most restrictive regarding clusters (Model 7) - including distance and sociodemographic variables.

\section{Impact of Green and Purchasing Power}

In the next step, we include the socioeconomic characteristics of environmental awareness (Green) and purchasing power $(P P)$ to see whether they increase the rental prices with their base effects and amplify the negative effect of the EPC value (log $(E P C))$ on the rental price. As postulated in $\mathrm{H} 1$, the more environmentally aware or economically powerful a neighborhood, the higher the monthly rent, (0.011) and (0.075), respectively; see Model 8 in Table 3. Thus, an increase of 1 percentage point in the Green vote would increase the monthly rent by $1.1 \%$, whereas an increase in purchasing power by $€ 10,000$ would increase the monthly rent by $7.5 \%$. These base effects of the two socioeconomic characteristics are also evident after controlling for 2way and 3-way interactions (see Model 9). Following our theoretical approach in section "Theoretical Background and Hypotheses Development", we assume that the more green or the higher the purchasing power of a neighborhood, the higher the discount for an increase in the EPC value. These hypotheses $(\mathrm{H} 2 \mathrm{a} / \mathrm{b})$ are confirmed by 
Table 3 Impact of Green and Purchasing Power

\begin{tabular}{|c|c|c|c|c|c|}
\hline & Model 8 & Model 9 & Model 10 & Model 11 & Model 12 \\
\hline $\log (E P C)$ & $\begin{array}{l}-0.020 * * * \\
(0.001)\end{array}$ & $\begin{array}{l}0.003 \\
(0.014)\end{array}$ & $\begin{array}{l}0.011 \\
(0.013)\end{array}$ & $\begin{array}{l}-0.008 \\
(0.015)\end{array}$ & $\begin{array}{l}0.030 * * \\
(0.014)\end{array}$ \\
\hline Green & $\begin{array}{l}0.011 * * * \\
(0.000)\end{array}$ & $\begin{array}{l}0.044 * * * \\
(0.005)\end{array}$ & $\begin{array}{l}0.067 * * * \\
(0.007)\end{array}$ & $\begin{array}{l}0.061^{* * *} \\
(0.006)\end{array}$ & $\begin{array}{l}0.055^{* * * *} \\
(0.005)\end{array}$ \\
\hline$P P$ & $\begin{array}{l}0.075 * * * \\
(0.001)\end{array}$ & $\begin{array}{l}0.212^{* * * *} \\
(0.015)\end{array}$ & $\begin{array}{l}0.214 * * * \\
(0.014)\end{array}$ & $\begin{array}{l}0.157 * * * \\
(0.016)\end{array}$ & $\begin{array}{l}0.243 * * * \\
(0.016)\end{array}$ \\
\hline $\log (E P C) \times$ Green & & $\begin{array}{l}-0.003 * * * \\
(0.001)\end{array}$ & $\begin{array}{l}-0.005^{* * *} \\
(0.001)\end{array}$ & $\begin{array}{l}-0.004 * * * \\
(0.001)\end{array}$ & $\begin{array}{l}-0.005^{* * * *} \\
(0.001)\end{array}$ \\
\hline $\log (E P C) \times P P$ & & $\begin{array}{l}-0.016^{* * * *} \\
(0.003)\end{array}$ & $\begin{array}{l}-0.017 * * * \\
(0.003)\end{array}$ & $\begin{array}{l}-0.014 * * * \\
(0.003)\end{array}$ & $\begin{array}{l}-0.022 * * * \\
(0.003)\end{array}$ \\
\hline Green x $P P$ & & $\begin{array}{l}-0.012 * * * \\
(0.001)\end{array}$ & $\begin{array}{l}-0.017 * * * \\
(0.001)\end{array}$ & $\begin{array}{l}-0.012 * * * \\
(0.001)\end{array}$ & $\begin{array}{l}-0.014 * * * \\
(0.001)\end{array}$ \\
\hline $\log (E P C) \times$ Green $\times P P$ & & $\begin{array}{l}0.002 * * * \\
(0.000)\end{array}$ & $\begin{array}{l}0.002^{* * * *} \\
(0.000)\end{array}$ & $\begin{array}{l}0.002^{* * *} \\
(0.000)\end{array}$ & $\begin{array}{l}0.002 * * * \\
(0.000)\end{array}$ \\
\hline EPC Requirement & $\begin{array}{l}0.030 \text { *** } \\
(0.001)\end{array}$ & $\begin{array}{l}0.031 \text { *** } \\
(0.001)\end{array}$ & $\begin{array}{l}0.030 * * * \\
(0.001)\end{array}$ & $\begin{array}{l}0.032^{* * * *} \\
(0.001)\end{array}$ & \\
\hline EPC with Rating & $\begin{array}{l}0.014 * * * \\
(0.001)\end{array}$ & $\begin{array}{l}0.014 * * * \\
(0.001)\end{array}$ & $\begin{array}{l}0.014 * * * \\
(0.001)\end{array}$ & $\begin{array}{l}0.014 * * * \\
(0.001)\end{array}$ & \\
\hline $\log$ (Utilities' Cost) & $\begin{array}{l}0.021 * * * \\
(0.001)\end{array}$ & $\begin{array}{l}0.021 \text { *** } \\
(0.001)\end{array}$ & $\begin{array}{l}0.021^{* * * *} \\
(0.001)\end{array}$ & $\begin{array}{l}0.025^{* * * *} \\
(0.001)\end{array}$ & $\begin{array}{l}0.020 * * * \\
(0.001)\end{array}$ \\
\hline $\log$ (Heating Cost) & $\begin{array}{l}-0.007 * * * \\
(0.001)\end{array}$ & $\begin{array}{l}-0.006^{* * *} \\
(0.001)\end{array}$ & $\begin{array}{l}-0.006^{* * *} \\
(0.001)\end{array}$ & $\begin{array}{l}-0.003^{* *} \\
(0.001)\end{array}$ & \\
\hline Structural & Yes & Yes & Yes & Yes & Yes \\
\hline Distance & Yes & Yes & Yes & Yes & Yes \\
\hline Sociodemographic & Yes & Yes & Yes & No & Yes \\
\hline Time FE & Yes & Yes & Yes & Yes & Yes \\
\hline Spatial FE & Political & Political & Political & Political & Political \\
\hline SE cluster & Time/Spatial & Time/Spatial & Time/Spatial & Time/Spatial & Time/Spatial \\
\hline$N$ & 377,426 & 377,426 & 377,426 & 377,426 & 378,453 \\
\hline Adj. $\mathrm{R}^{2}$ & 0.718 & 0.720 & 0.720 & 0.697 & 0.718 \\
\hline
\end{tabular}

Based on Model 7 of the previous table, this table shows the sensitivity of the energy-related variables and socioeconomic variables (Green) and $(P P)$. In Model 8, we focus on the base effects of the key explanatory variables. In Model 9, we add their interaction terms. In Model 10, we do not use the state election in 2012 but the federal election in 2013 for Green. In Model 11, we exclude other sociodemographic variables (household size, number of households, immigration rate, unemployment rate). In Model 12, we exclude other energyrelated variables (EPC Requirement, EPC with Rating, and log (Heating Cost)). For more details about the model specification and variable definitions, see Table 2. * $p<0.1$, ** $p<0.05$, *** $p<0.01$

the two statistically significant interaction terms $(\log (E P C) \mathrm{x}$ Green $)$ and $(\log (E P C) \mathrm{x}$ $P P)$. We observe a negative impact of $\log (E P C) \times$ Green $(-0.003)$ and $\log (E P C) \times P P$ $(-0.016)$ using the state election of 2012 as a proxy for green awareness. In Model 10, we verify that these terms are about the same $(-0.005$ and -0.017$)$ and statistically significant by using the federal election of 2013; the Green Party achieved on average a 
lower result in this election (8.8\%) than in 2012 (12.5\%); see Table 1. In Model 11, we exclude the other sociodemographic variables (household size, number of households, immigration rate, unemployment rate) and find that the coefficients are stable. The base and interaction effects are also operating if we exclude other energy-related variables (EPC Requirement, EPC with Rating, and log (Heating Cost) in Model 12.

Comparing the results of the different specifications (Models 9-12), we find that the discount for higher EPC values is higher if a neighborhood is more green or has higher purchasing power. We conclude that Model 9 is the best, based on the various control variables and adjusted $R^{2}$. However, it is not so easy to compare the different base effects and interaction terms involved in a 3-way interaction regression at the same time. Thus, we compute the slopes for various combinations of all three variables (log $(E P C)$, Green, and $P P$ ) and show them in a margin plot (Fig. 1). In this figure, we compare the unconditional average partial effects (APEs) in the regression setting of Model 9 and choose three exemplary values (25\% percentile, median, and $75 \%$ percentile) for the two mediator variables (Green and $P P$ ) and plot their slopes over the $\log (E P C)$ values (1\%-99\% range). The three exemplary values are 9.8\%, $12.0 \%$, and $13.9 \%$ for Green, and $€ 37,250, € 41,881$, and $€ 46,694$ for $P P$, respectively. The underlying table with the 18 slopes is available from the authors upon request.

For all nine combinations, we see a decreasing slope for increasing EPC values. However, the slopes are more negative for the lowest group of Green (25\%) and the highest group of $P P(75 \%)$ with the most negative discount for the group (Green $(25 \%)$ $\mathrm{x} P P(75 \%)$ ). This combination penalizes an increase of $\log (E P C)$ value from 2.9 (EPC rating: $\left.\mathrm{A}^{+}\right)$to 5.7 (EPC rating: $\left.\mathrm{H}\right)$ with a rent decrease of $0.086(=2.01-1.92$; see Fig. 1). This discount of around $8.6 \%$ corresponds to an economic significance for a "mean" apartment of around $€ 48$ for each month (means are $€ 7.38$ for monthly rent and 71.7 sqm for size; see Table $1 ; € 47.62=(2.01-1.92) \cdot 7.38 \cdot 71.7)$.

If we take all interaction terms into account, we see that the group of the lowest results for the Green Party (25\%) for all three purchasing power groups $(25 \%, 50 \%$, $75 \%$ ) has a discount of around $8.4 \%$ if the EPC value increases from the lowest to the

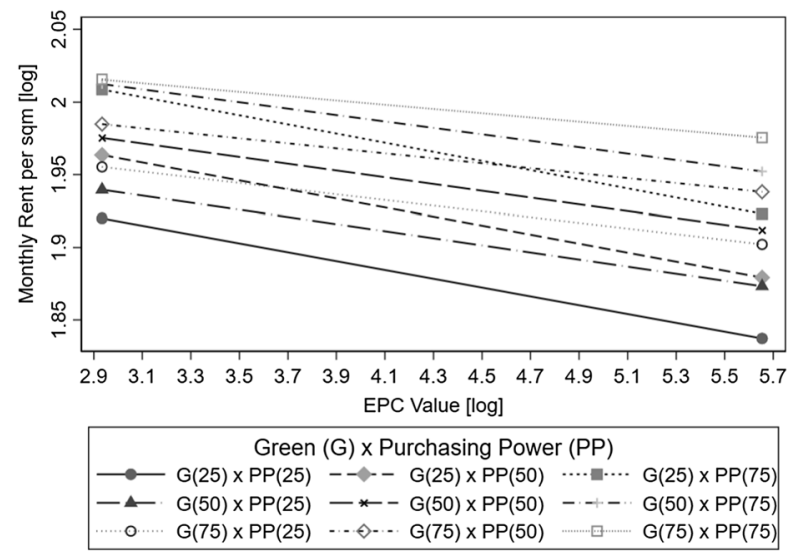

Fig. 1 Marginal Effects, This figure shows the marginal effects of environmental awareness (Green) and financial situation $(P P)$ over the range of the EPC Value $(\log (E P C))$ on the monthly base rent $(\log (R))$. The slopes are calculated for nine combinations of the two socioeconomic variables: 25 percentile (25), median (50), and 75 percentile (75). This figure was created with Stata/MP 15 
highest point. The corresponding number for the highest group of Green (75\%) is 4.7\%. This underlines that high purchasing power exerts a greater influence than green awareness on rent reduction in a neighborhood.

\section{Mandatory Disclosure and Time-Sensitivity of Green and Purchasing Power}

As discussed in section "Theoretical Background and Hypotheses Development", EPC labels issued after May 2014 are required to display energy efficiency in letters from $\mathrm{A}^{+}$ to $H$. This rating makes it easier for tenants to compare energy efficiency and may have amplified the effects on the energy-related variables. Although the regulation was effective from May 2014, landlords had a phase-in period of one year, so we assume that May 2015 is the conclusive date to test whether there is a significant difference between the voluntary period (before May 2014) and the mandatory period (after May 2015). Thus, we split our sample into three periods by using Model 9: before May 2014, between May 2014 and May 2015, and after May 2015.

In Table 4, we can confirm that the two most relevant interaction terms $(\log (E P C) \mathrm{x}$ Green $)$ and $(\log (E P C) \times P P)$ increased their negative impact after May 2015. The respective figures are -0.006 for $(\log (E P C) \times$ Green $)$ and -0.027 for $(\log (E P C) \times P P)$; both effects are stronger than for the entire period (see Table 3) and only significant after May 2015 (log $(E P C) \times$ Green) and May $2014(\log (E P C) \times P P)$. The base effect of $\log (E P C)$ is significantly positive since May 2015 as for the entire period.

At first sight, this may lead to the conclusion that the policy changes after May 2015 increased or even triggered (not significant before) the negative effect for higher EPC labels in green neighborhoods. However, we want to determine whether this is effect occurred immediately after May 2015 or was only recently $(2017,2018$, etc.) activated. Therefore, we separate our sample in smaller windows in the next step.

In view of the potential limitations, we take a closer look at the stability of the effects over time without any specific date of a policy change. The whole observation period from Q1 2007 to Q1 2019 is split into 2-year windows (2 $\frac{1}{4}$ for the last window) by using Model 9. Again, we are particularly interested in whether the effect of green awareness on the price reduction has risen over the years (see H3 in section "Theoretical Background and Hypotheses Development") and whether it was even present in the early years. In the context of the previous findings (significant after May 2015), we want to determine when it reached higher values post 2015. In Table 5, we observe that $\log (E P C)$ is not significant for the first years and then alternates between negative and positive effects from 2014; a negative effect due to an increase in the energy consumption was only present between 2015 and 2016. The base effects of Green and PP are constantly positive and significant since 2013; both effects increased during the last window (2017-2019).

The interactions of the socioeconomic variables with $\log (E P C)$ are only evident since 2017. Thus, the finding that greener or economically more powerful neighborhoods reduce their rent for energy-inefficient apartments is mostly seen since then. The dummy effect of the EPC label (EPC Requirement) is consistently positive and significant over the entire period. The additional information with a letter for the EPC (EPC with Rating) is significantly positive since but not directly after its obligatory disclosure in May 2015. A $1 \%$ increase in heating costs decreases the monthly rent by $0.5-0.8 \%$ since 2013 ; interestingly, it 
Table 4 Voluntary vs. Mandatory EPC Rating Disclosure

Model 9

\begin{tabular}{|c|c|c|c|}
\hline & before May 2014 & between May 2014 and May 2015 & after May 2015 \\
\hline \multirow[t]{2}{*}{$\log (E P C)$} & $-0.063 * *$ & 0.001 & $0.040 * *$ \\
\hline & $(0.028)$ & $(0.032)$ & $(0.019)$ \\
\hline \multirow[t]{2}{*}{ Green } & 0.012 & $0.048 * * *$ & $0.060 * * *$ \\
\hline & $(0.010)$ & $(0.012)$ & $(0.007)$ \\
\hline \multirow[t]{2}{*}{$P P$} & $0.112 * * *$ & $0.239 * * *$ & $0.268 * * *$ \\
\hline & $(0.030)$ & $(0.034)$ & $(0.020)$ \\
\hline \multirow[t]{2}{*}{$\log (E P C) \times$ Green } & 0.002 & -0.003 & $-0.006^{* * *}$ \\
\hline & $(0.002)$ & $(0.002)$ & $(0.001)$ \\
\hline \multirow[t]{2}{*}{$\log (E P C) \times P P$} & 0.002 & $-0.018 * *$ & $-0.027 * * *$ \\
\hline & $(0.006)$ & $(0.007)$ & $(0.004)$ \\
\hline \multirow[t]{2}{*}{ Green x $P P$} & $-0.004 *$ & $-0.013 * * *$ & $-0.016 * * *$ \\
\hline & $(0.002)$ & $(0.003)$ & $(0.002)$ \\
\hline \multirow[t]{2}{*}{$\log (E P C) \times$ Green $\times P P$} & 0.000 & $0.002 * * *$ & $0.002 * * *$ \\
\hline & $(0.000)$ & $(0.001)$ & $(0.000)$ \\
\hline \multirow[t]{2}{*}{ EPC Requirement } & $0.024 * * *$ & $0.031^{* * *}$ & $0.034 * * *$ \\
\hline & $(0.001)$ & $(0.001)$ & $(0.001)$ \\
\hline \multirow[t]{2}{*}{ EPC with Rating } & $0.012 * * *$ & $0.016^{* * *}$ & $0.014 * * *$ \\
\hline & $(0.003)$ & $(0.002)$ & $(0.001)$ \\
\hline \multirow[t]{2}{*}{$\log ($ Utilities' Cost $)$} & $0.017 * * *$ & $0.027 * * *$ & $0.020 * * *$ \\
\hline & $(0.002)$ & $(0.003)$ & $(0.002)$ \\
\hline \multirow[t]{2}{*}{$\log ($ Heating Cost $)$} & 0.004 & $-0.005^{*}$ & $-0.008 * * *$ \\
\hline & $(0.003)$ & $(0.003)$ & $(0.002)$ \\
\hline Structural & Yes & Yes & Yes \\
\hline Distance & Yes & Yes & Yes \\
\hline Sociodemographic & Yes & Yes & Yes \\
\hline Time FE & Yes & Yes & Yes \\
\hline Spatial FE & Political & Political & Political \\
\hline SE cluster & Time/Spatial & Time/Spatial & Time/Spatial \\
\hline$N$ & 109,990 & 73,873 & 193,563 \\
\hline Adj. $\mathrm{R}^{2}$ & 0.673 & 0.732 & 0.730 \\
\hline
\end{tabular}

Based on Model 9 of Table 3, this table shows the time-sensitivity of the energy-related variables and socioeconomic variables (Green) and $(P P)$ before/after a regulation change. After May 2014, EPC labels are required to display the energy value in letters, too. The phase-in period was one year, so that, we split our sample into three periods: before May 2014, between May 2014 and May 2015, and after May 2015. For more details about the model specification and variable definitions, see Table 3 . * $p<0.1$, ** $p<0.05$, *** $p<0.01$

even had a positive effect between 2011 and 2012. The adjusted $R^{2}$ has increased constantly across the time period from $60.6 \%$ to $73.1 \%$. This may be also driven by a broader variance in the apartments' attributes since the observation number is rather small for the first years: namely 8675 for 2007-2008 compared with 88,906 in 2017-2019. 
Table 5 Time-sensitivity of Green and Purchasing Power

\begin{tabular}{|c|c|c|c|c|c|c|}
\hline & \multicolumn{6}{|l|}{ Model 9} \\
\hline & $\begin{array}{l}(2007- \\
2008)\end{array}$ & $\begin{array}{l}(2009- \\
2010)\end{array}$ & $\begin{array}{l}(2011- \\
2012)\end{array}$ & $\begin{array}{l}(2013- \\
2014)\end{array}$ & $\begin{array}{l}(2015- \\
2016)\end{array}$ & $\begin{array}{l}(2017- \\
2019)\end{array}$ \\
\hline \multirow[t]{2}{*}{$\log (E P C)$} & 0.023 & -0.074 & -0.081 & -0.049 & $-0.077 * * *$ & $0.184 * * *$ \\
\hline & $(0.101)$ & $(0.056)$ & $(0.050)$ & $(0.031)$ & $(0.024)$ & $(0.028)$ \\
\hline \multirow[t]{2}{*}{ Green } & 0.024 & 0.008 & 0.011 & $0.025 * *$ & $0.022 * *$ & $0.111^{* * *}$ \\
\hline & $(0.036)$ & $(0.020)$ & $(0.018)$ & $(0.011)$ & $(0.009)$ & $(0.010)$ \\
\hline \multirow[t]{2}{*}{$P P$} & $0.193 *$ & 0.088 & $0.097 *$ & $0.173 * * *$ & $0.155^{* * *}$ & $0.412 * * *$ \\
\hline & $(0.107)$ & $(0.062)$ & $(0.054)$ & $(0.033)$ & $(0.025)$ & $(0.030)$ \\
\hline \multirow[t]{2}{*}{$\log (E P C) \times$ Green } & -0.003 & 0.002 & 0.003 & 0.002 & 0.003 & $-0.017 * * *$ \\
\hline & $(0.008)$ & $(0.004)$ & $(0.004)$ & $(0.002)$ & $(0.002)$ & $(0.002)$ \\
\hline \multirow[t]{2}{*}{$\log (E P C) \times P P$} & -0.019 & 0.006 & 0.006 & -0.005 & -0.002 & $-0.058 * * *$ \\
\hline & $(0.022)$ & $(0.013)$ & $(0.011)$ & $(0.007)$ & $(0.005)$ & $(0.006)$ \\
\hline \multirow[t]{2}{*}{ Green x $P P$} & -0.008 & -0.003 & -0.003 & $-0.008 * * *$ & $-0.007 * * *$ & $-0.027 * * *$ \\
\hline & $(0.008)$ & $(0.005)$ & $(0.004)$ & $(0.002)$ & $(0.002)$ & $(0.002)$ \\
\hline \multirow{2}{*}{$\begin{array}{l}\log (E P C) \times \text { Green } \times \\
\quad P P\end{array}$} & 0.001 & 0.000 & -0.000 & 0.001 & 0.000 & $0.005 * * *$ \\
\hline & $(0.002)$ & $(0.001)$ & $(0.001)$ & $(0.001)$ & $(0.000)$ & $(0.000)$ \\
\hline \multirow[t]{2}{*}{ EPC Requirement } & $0.014^{* * * *}$ & $0.016^{* * *}$ & $0.024 * * *$ & $0.031 * * *$ & $0.033 * * *$ & $0.033 * * *$ \\
\hline & $(0.004)$ & $(0.002)$ & $(0.002)$ & $(0.001)$ & $(0.001)$ & $(0.001)$ \\
\hline \multirow[t]{2}{*}{ EPC with Rating } & -0.006 & 0.004 & $0.015^{* * *}$ & $0.017 * * *$ & $0.015^{* * *}$ & $0.014 * * *$ \\
\hline & $(0.012)$ & $(0.008)$ & $(0.005)$ & $(0.002)$ & $(0.001)$ & $(0.001)$ \\
\hline \multirow[t]{2}{*}{$\log \left(\right.$ Utilities' Cost $^{\prime}$} & 0.004 & $0.016^{* * *}$ & $0.022 * * *$ & $0.022 * * *$ & $0.026^{* * * *}$ & $0.016^{* * *}$ \\
\hline & $(0.002)$ & $(0.003)$ & $(0.003)$ & $(0.003)$ & $(0.002)$ & $(0.003)$ \\
\hline \multirow[t]{2}{*}{$\log ($ Heating Cost $)$} & 0.007 & 0.001 & $0.022 * * *$ & $-0.007 * *$ & $-0.005 * * *$ & $-0.008 * * *$ \\
\hline & $(0.012)$ & $(0.006)$ & $(0.007)$ & $(0.003)$ & $(0.002)$ & $(0.002)$ \\
\hline Structural & Yes & Yes & Yes & Yes & Yes & Yes \\
\hline Distance & Yes & Yes & Yes & Yes & Yes & Yes \\
\hline Sociodemographic & Yes & Yes & Yes & Yes & Yes & Yes \\
\hline Time FE & Yes & Yes & Yes & Yes & Yes & Yes \\
\hline Spatial FE & Political & Political & Political & Political & Political & Political \\
\hline SE cluster & Time/Spatial & Time/Spatial & Time/Spatial & Time/Spatial & Time/Spatial & Time/Spatial \\
\hline$N$ & 8675 & 30,945 & 36,346 & 82,737 & 129,817 & 88,906 \\
\hline Adj. $\mathrm{R}^{2}$ & 0.606 & 0.647 & 0.672 & 0.721 & 0.731 & 0.731 \\
\hline
\end{tabular}

Based on Model 9 of Table 3, this table shows the time-sensitivity of the energy-related variables and socioeconomic variables (Green) and $(P P)$ in 2-year windows over the sample period January 2007 to March 2019. For more details about the model specification and variable definitions, see Table 3 . $* p<0.1$, $* * p<0.05, * * * p<0.01$

In summary, the negative interaction of higher EPC values on rental prices in greener and economically more powerful neighborhoods are mostly driven by the observation period post 2017. The base effects of these socioeconomic variables - greener and economically more powerful neighborhoods pay a higher rent - are active from 2011 and 2013, respectively. 


\section{Conclusion}

In this study, we analyze the reason for lower rents for energy-inefficient apartments. We identify theoretically the drivers of this effect: cost of energy consumption, green awareness, purchasing power or a combination of these factors. Furthermore, we use our sample to test whether a regulation requiring mandatory disclosure of the EPC figures, effective since May 2014/2015, triggers or strengthens the effect of higher energy consumption in terms of decreasing rents.

In contrast to Sexton and Sexton (2014), who explain the prosocial behavior of environmentalists with "conspicuous conservation", it is unclear whether renting a "greener" apartment is as adequate for displaying green behavior as driving a hybrid or electric car. The motivation of such renters is consequently more intrinsically activated or evidence that environmentalists act as they preach. Over recent years, people's environmental awareness and the influence of the Green parties on policies and housing regulations have increased, especially in Germany. Thus, we check whether it is this higher environmental awareness, higher purchasing power, or higher energy expenditure that drives the rent reduction.

With a simple model, we verify previous research that a higher EPC value decreases the rent, even after controlling for the energy expenditure. Furthermore, our findings suggest that neighborhoods with higher green awareness and higher purchasing power pay lower rents for energy-inefficient apartments. However, taking all interaction terms into account, we find that communities located in neighborhoods with low green awareness and high purchasing power have the highest negative slope for increasing energy consumption $\left(-8.6 \%\right.$ from $\mathrm{A}^{+}$to $\left.\mathrm{H}\right)$. Thus, the effects of purchasing power are higher than for green awareness.

As in other research (e.g. Bond and Devine 2016), we find that additional or more valuable information about an apartment's energy consumption increases the rent; this might be through a better EPC type or if the rating $\left(\mathrm{A}^{+}\right.$to $\left.\mathrm{H}\right)$ is additionally stated. Most of the effect of green neighborhoods is not directly triggered by the mandatory disclosure of EPC figures but rather two years later. Therefore, it seems that the gain in environmental awareness - possibly in combination with mandatory requirements and a consequently more transparent market - is the main driver.

Our findings reveal that there is a heterogeneity in the negative effect of higher energy consumption on rents, beyond the direct energy expenditure. These are not mostly driven by environmental awareness possibly since the "conspicuous conservation" is not so clear for a green apartment. More research regarding a higher granularity of socioeconomic factors (building level) and more factors may help regulators to improve the strategic goal of their energy-saving programs as an instrument of energy and climate protection, and to reach a nearly climate-neutral building stock. However, we leave this as a goal for future research.

Acknowledgements The authors thank Shaun Bond, Piet Eichholtz, Rogier Holtermans, Avis Devine, Spenser Robinson, and Drew Sanderford and the participants of the ReCapNet Conference in Mannheim, Germany, of the ARES Annual Meeting in San Diego, USA, and of the AREUEA International Conference in Amsterdam, the Netherlands, for their insightful comments and suggestions on an earlier version of this paper. Finally, we would like to thank the RWI - Leibniz-Institut für Wirtschaftsforschung, Immobilien Scout $\mathrm{GmbH}$, and Verivox $\mathrm{GmbH}$ for providing us with raw data. 
Funding Information Open access funding provided by Royal Institute of Technology. This research project was partly funded by the Ministry of Culture and Science of the German State of North RhineWestphalia (MKW) within the framework of the Competence Center of Consumer Research North RhineWestphalia (CECORE NRW). The CECORE NRW is a cooperation project of the MKW with the Consumer Association of North Rhine-Westphalia and the Ministry for Environment, Agriculture, Conservation and Consumer Protection of the German State of North Rhine-Westphalia (MULNV).

\section{Compliance with Ethical Standards}

Conflict of Interest The authors declare that they have no conflict of interest.

Open Access This article is licensed under a Creative Commons Attribution 4.0 International License, which permits use, sharing, adaptation, distribution and reproduction in any medium or format, as long as you give appropriate credit to the original author(s) and the source, provide a link to the Creative Commons licence, and indicate if changes were made. The images or other third party material in this article are included in the article's Creative Commons licence, unless indicated otherwise in a credit line to the material. If material is not included in the article's Creative Commons licence and your intended use is not permitted by statutory regulation or exceeds the permitted use, you will need to obtain permission directly from the copyright holder. To view a copy of this licence, visit http://creativecommons.org/licenses/by/4.0/.

\section{References}

Aydin, E., Kok, N., \& Brounen, D. (2017). Energy efficiency and household behavior: The rebound effect in the residential sector. RAND Journal of Economics, 48(3), 749-782.

Aydin, E., Brounen, D., \& Kok, N. (2018). Information provision and energy consumption: Evidence from a field experiment. Energy Economics, 71, 403-410.

Boelmann, B., \& Schaffner, S. (2018). FDZ data description: Real-estate data for Germany (RWI-GEO-RED): Advertisements on the internet platform lmmobilienScout24, RWI Projektberichte.

Bond, S. A., \& Devine, A. (2016). Certification matters: Is green talk cheap talk? Journal of Real Estate Finance and Economics, 52(2), 117-140.

Brounen, D., \& Kok, N. (2011). On the economics of energy labels in the housing market. Journal of Environmental Economics and Management, 62(2), 166-179.

Brounen, D., Kok, N., \& Quigley, J. M. (2013). Energy literacy, awareness, and conservation behavior of residential households. Energy Economics, 38, 42-50.

Eichholtz, P., Kok, N., \& Quigley, J. M. (2010). Doing well by doing good? Green office buildings. American Economic Review, 100(5), 2492-2509.

Eurostat (2018). Living conditions in Europe: 2018 edition, Luxembourg.

Fowlie, M., Greenstone, M., \& Wolfram, C. (2015). Are the non-monetary costs of energy efficiency investments large? Understanding low take-up of a free energy efficiency program. American Economic Review: Papers \& Proceedings, 105(5), 201-204.

Fuerst, F., McAllister, P., Nanda, A., \& Wyatt, P. (2015). Does energy efficiency matter to home-buyers? An investigation of EPC ratings and transaction prices in England. Energy Economics, 48, 145-156.

Fuerst, F., McAllister, P., Nanda, A., \& Wyatt, P. (2016a). Energy performance ratings and house prices in Wales: An empirical study. Energy Policy, 92, 20-33.

Fuerst, F., Oikarinen, E., \& Harjunen, O. (2016b). Green signaling effects in the market for energy-efficient residential buildings. Applied Energy, 180, 560-571.

Gamba, R. J., \& Oskamp, S. (2016). Factors influencing community residents' participation in commingled curbside recycling programs. Environment and Behavior, 26(5), 587-612.

Hilber, C. A. L. (2005). Neighborhood externality risk and the homeownership status of properties. Journal of Urban Economics, 57(2), 213-241.

Kahn, M. E. (2007). Do greens drive hummers or hybrids? Environmental ideology as a determinant of consumer choice. Journal of Environmental Economics and Management, 54(2), 129-145.

Kahn, M. E., \& Kok, N. (2014). The capitalization of green labels in the California housing market. Regional Science and Urban Economics, 47(2014), 25-34. 
Kok, N., \& Jennen, M. (2012). The impact of energy labels and accessibility on office rents. Energy Policy, 46, $489-497$.

Kosfeld, R., \& Werner, A. (2012). Deutsche Arbeitsmarktregionen: Neuabgrenzung nach den Kreisgebietsreformen 2007-2011. Raumforschung und Raumordnung | Spatial Research and Planning, $70(1), 49-64$.

Lucon, O., Ürge-Vorsatz, D., Zain Ahmed, A., Akbari, H., Bertoldi, P., Cabeza, L. F., Eyre, N., Gadgil, A. Harvey, L. D. D., Jiang, Y., Liphoto, E., Mirasgedis, S., Murakami, S., Parikh, J., Pyke, C., \& Vilariño, M. V. (2014). Buildings. In: Climate Change 2014: Mitigation of Climate Change. Contribution of working group III to the fifth assessment report of the intergovernmental panel on climate change. Cambridge: Cambridge University Press.

Mandell, S., \& Wilhelmsson, M. (2011). Willingness to pay for sustainable housing. Journal of Housing Research, 20(1), 35-51.

NRW.Bank (2018). Wohneigentum in Nordrhein-Westfalen Trends, Rahmenbedingungen und Förderansätze, Düsseldorf.

Sexton, S. E., \& Sexton, A. L. (2014). Conspicuous conservation: The Prius halo and willingness to pay for environmental bona fides. Journal of Environmental Economics and Management, 67(3), 303-317.

Yavas, A., \& Yang, S. (1995). The strategic role of listing Price in marketing real estate: Theory and evidence. Real Estate Economics, 23(3), 347-368.

Publisher's Note Springer Nature remains neutral with regard to jurisdictional claims in published maps and institutional affiliations. 